\title{
The Analysis of Automotive Starter's Common Broken Gear
}

\author{
$\mathrm{Na}$ Yang $^{1}$ and Kun $\mathrm{Wu}^{2}$ \\ ${ }^{1}$ Mechanical and electrical technology department Xijing University, Shaanxi Xi'an, China \\ 515569778@qq.com
}

Keywords: Drive gear; Broken teeth; The strength of Drive gear

\begin{abstract}
Also known as the starter motor or starter motor, the main role is that the electric energy of battery is converted into mechanical energy to drive the engine flywheel rotating, thus starting the engine. This paper is Electromagnetic soft starter meshing and Engine for gas engine. The main parts of the drive gear as the starter drive, is used to output torque of the engine flywheel ringing, with high transmission efficiency, compact structure, stable transmission characteristics and so on. Natural gas engines and diesel engines require the drive gear to withstand frequent alternating torque. The analysis of the working process curve of starter find out the reasons of broken teeth and solving plan, and the final conclusion is that the main factor causing failure driven gear failure driving gear strength, engine cylinder number, starting when the average drag current.
\end{abstract}

\section{Introduction}

From the industry data observation, broken teeth in the starter failure rate accounted for a relatively small, but with the popularization and application of natural gas engine, the data is synchronized to upgrade.

\section{The Working Principle of Starter}

The Working Principle of Starter. As everyone knows, the automobile starter played a starting engine role. As a whole, the starter is mainly composed of three parts to achieve the whole starting process. The DC motor converts electrical energy from the battery into mechanical energy, that is to say that driving gear produces mechanical motion; the transmission mechanism makes the starter shaft drive pinion meshing flywheel ring gear. Starter transfer torque to the engine crank shaft, and after the start of the engine starter pinion and flywheel gear disengage automatically; Starter electromagnetic switch control circuit.

The Structure of Starter. Control device of automobile starter was mainly composed of electromagnetic switch, starting relay and ignition switch etc.

Electromagnetic switch is mainly composed of two parts, that is electromagnet mechanism and motor switch. The electromagnet mechanism is composed of a movable iron core, a fixed iron core, a pull coil and a holding coil. Fixed core as the name suggests is fixed, the movable core can be axially moved in the copper sleeve [1]. The push rod is fixed at the front end of the movable iron core, and the switch contact disc is arranged on the front end of the push rod. The reset spring is arranged on the outer end of the copper sleeve and is used for resetting the movable parts such as the movable core.

When the starter is starting, the pulling coil and the holding coil. At the same time, the pulling coil and the holding coil have the same direction of the magnetic field, then electromagnetic attractive superpose. The movable iron core overcomes the elasticity of the reset spring to move forward, so that the contact plate of the front end of the push rod is connected with the electric switch contact to make the main circuit of the motor turn on. When ignition switch leaves off starting, the direction of the magnetic field produced by the pulling and holding coil is contrary, that is magnetic adhesion were canceled out. Under the action of the reset spring, the movable parts such as the movable core and the like can be automatically reset. 
The starter circuit consists of control circuit and main circuit. The control circuit is mainly composed of a starting relay and an electromagnetic starting circuit. The start relay is controlled by the ignition switch. When the ignition switch is turned on, the current is from the battery positive terminal to the power supply after the starter, ignition switch, and then back to the negative terminal of the battery from the relay coil. Relay core generates electromagnetic attraction, so that the relay electric closed control circuit connected starter electromagnetic switch, main circuit shown in Fig. 1. After the electromagnetic switch is switched on, the pulling coil 6 and holding coil 8 produce strong electromagnetic force, then the main circuit connected to the starter. Battery cathode $\rightarrow$ power supply terminal of the starter $\rightarrow$ Electromagnetic switch $\rightarrow$ Excitation winding $\rightarrow$ Armature winding $\rightarrow$ Ground $\rightarrow$ Battery negative electrode, Then the starter electromagnetic torque, starting the engine[3]-[4].

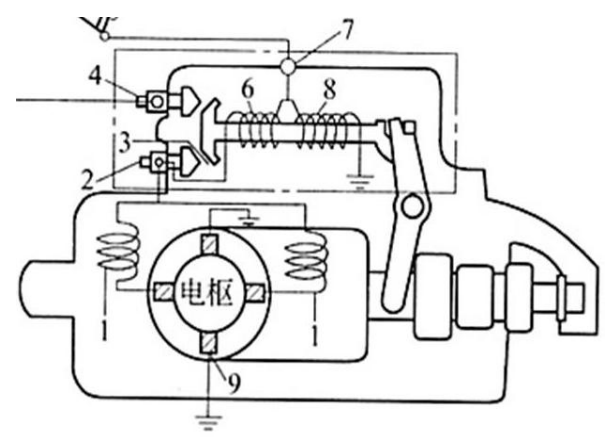

Figure 1. Structure diagram of the Starter

Gear Failure Mode. Tooth surface wear

For gear or gear transmission with clean oil, there will be relatively sliding engagement between the tooth surface, make some hard abrasive particles into the friction surface, so that the tooth profile changes, backlash increase, resulting in excessive thinning or even broken tooth gear. Under normal circumstances, only in the lubricating oil mixed with abrasive particles, gear will cause tooth wear in the process of operation.

Fatigue pitting

When the two gears are engaged with each other, the contact force between the tooth surface and the reaction force causes the contact stress of the two working surface.

Because the gear is a periodic motion, and the position of the meshing point is changed, the contact stress is changed according to the pulsation cycle. Long time in the contact stress under the action of the tooth surface of the marks will appear small crack. With the passage of time, the cracks in the surface transverse crack gradually extended into the ring, to produce tiny mind and the formation of fatigue spelling shallow tooth surface

Tooth surface bonding

Some large tooth surface friction, relative velocity, especially in high speed and heavy load gear transmission in the meshing zone temperature is too high, once the bad condition of the lubricating oil film body, tooth surface inspection will disappear, the metal surface of two teeth between direct contact, mutual adhesion.

Broken teeth

As a cantilever beam, in the process of loading the load of the gear, the root of the periodic pulse stress exceeds the fatigue limit of the gear material, it will produce cracks in the root and gradually expand. When the rest cannot bear the load transmission will occur when the tooth breaking phenomenon. In the work of the serious impact, bias and uneven material can also lead to broken teeth.

The deformation of 5 tooth shape

In the heavy load or impact load, the tooth surface deformation of local shape, from the surface deformation of the involute tooth profile. 


\section{Fault Phenomenon of Gear Tooth Broken}

Starter driving gear in the process, there is a transition area of tooth root quenching area and Non Hardened Zone of the residual tensile stress, and the root of the tooth working stress is tensile stress. When the superposition of the two is more than the peak of the tensile stress, the fatigue strength of the gear will be reduced. Further strengthening of the crack, it will reverse gear broken tooth fault. This kind of fracture is usually started from the root of the gear, and the fracture and broken tooth residue will generally form 40 to 45 degrees. As is shown in Fig. 2.



Figure 2. Broken tooth failure

\section{The Cause Analysis}

Analysis on Broken Tooth of Starter. Analysis of transient process of starter. As is shown in Fig. 3.

In the process of starting the engine starter collected. When the mixed gas in the cylinder is compressed for the first time [8], starter one-way clutch wedge in the state. When the mixed gas open cylinder combustion working gear ring, the angular velocity increased rapidly, resulting in a one-way clutch wedge in the instantaneous state of no-load state even weakened, this time due to mixed gas did not completely burn up. When the gas mixture in the cylinder is compressed again, the angular velocity of the gear ring decreases rapidly, which causes the one-way clutch to be in a wedge state again. At this moment, the driving gear alternately appears wedge and unload state, which can bear the repeated impact torque, and cause the violent vibration of the driving gear.

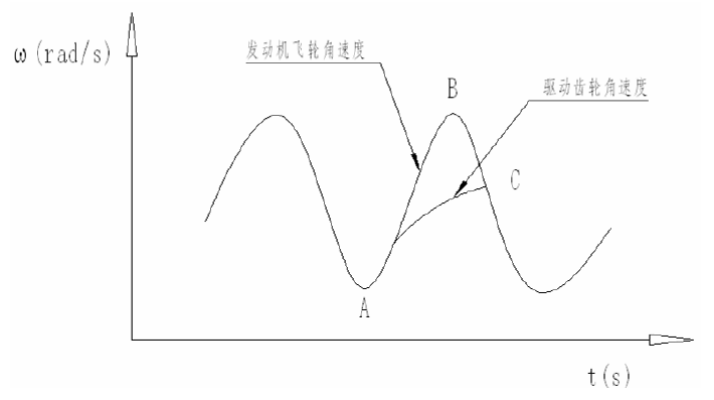

Figure 3. PICO test curve

Electromagnetic Torque Effect Analysis. As is shown in Fig. 4. When the magnetic circuit is not saturated, the armature electromagnetic torque is proportional to the square of the current. When the magnetic circuit is saturated, the electromagnetic torque and current. When the driving current is small, the working area is in the saturation region of the magnetic circuit. At this time, the electromagnetic torque of the armature is greatly influenced by the current. This fluctuation is applied to the drive gear at the start of the moment and the gears are subjected to severe shock. 




Figure 4. Starting performance curve

\section{Conclusions}

Thorough the above analysis, the following measures are put forward:

Enhanced gear strength. By changing gears, tooth root fillet, layer, tooth number, material and other aspects to improve the strength of gear, using DOE method to find the optimal combination of these parameters.

The working interval close to the maximum point direction, the armature electromagnetic torque current fluctuation amplitude decreases, can be carried out through the following two ways: teeth;

Increase reduction ratio. Using four planetary gear reducer or increase the number of driving gear

Reduce starter power: Increase the air gap between the stator and armature.

\section{References}

[1] Dong Guo Xia. Automobile starter teeth broken in the gas machine application environment analysis and optimization design [D]. Jilin University, 2016, 10(12): 6-7.

[2] Zhu Ganggang. Automotive starter technology and its development trend [J]. Household appliances, 2006, 08:54-55+43.

[3] Wang Wen Lin. The development of automotive starter and its related technology [J]. Mechanical and electrical engineering, 2004, 06:55-59.

[4] Kashmir S.VIRK, UYGUR KOKTURK, GRAIG R.Bartels. Effects of Air on Diesel Engine Exhaust Emissions and Engine Performance[C]. SAE paper 1993, No.931004.

[5] MeiXiaoNing shu-xing Yang. Review the multidisciplinary design optimization of complex systems [J]. Journal of engineering design, 2010, (3): 173-180.

[6] RAMESH B. POOLA, HENRY K.NG, RAJ R.SEKAR, JOHN H. BAUDINO, Christopher P. Colucci. Utilizing Intake-Air Oxygen-Enrichment Technology to Reduce cold-Phase Emissions[C]. SAE paper 1996, No.961171.JiGuoHua, li yan, wenqiang li, etc. A multidisciplinary design optimization method for complex system [J]. Journal of mechanical design and research of 2011.27 (4): 6-11.

[7] W.J. WARTINBEE, JR. Emissions Study of Oxygen Enriched Air[C]. Society of Automotive Engineers, SAE paper 1971, No.710606.

[8] Xue Lipeng. Tilt rotor machine pneumatic/dynamics multidisciplinary design optimization research [D]. Nanjing: Nanjing University of aeronautics and astronautics. 2011. 